\title{
Regulation of AKT/AMPK signaling, autophagy and mitigation of apoptosis in Rutin-pretreated SH-SY5Y cells exposed to MPP ${ }^{+}$
}

\author{
Adaze Bijou Enogieru ${ }^{1,2}$ [D $\cdot$ William Haylett $^{3} \cdot$ Donavon Charles Hiss $^{1} \cdot$ Okobi Eko Ekpo $^{1}$ \\ Received: 17 August 2020 / Accepted: 30 October 2020 / Published online: 4 November 2020 \\ (C) Springer Science+Business Media, LLC, part of Springer Nature 2020
}

\begin{abstract}
Accumulating evidence suggest that apoptosis, autophagy and dysregulation of signaling pathways are common mechanisms involved in Parkinson's disease (PD) pathogenesis, and thus development of therapeutic agents targeting these mechanisms may be useful for the treatment of this disease. Although rutin (a bioflavonoid) is reported to have pharmacological benefits such as antioxidant, anti-inflammatory and antitumor activities, there are very few reports on the activity of this compound in 1-methyl-4phenylpyridinium $\left(\mathrm{MPP}^{+}\right)$-induced PD models. Accordingly, we investigated the effects of rutin on apoptosis, autophagy and cell signaling markers (AKT/AMPK) in SH-SY5Y cells exposed to MPP ${ }^{+}$. Results show reduced changes in nuclear morphology and mitigation of caspase $3 / 7$ and 9 activities in rutin pre-treated cells exposed to $\mathrm{MPP}^{+}$. Likewise, rutin regulated cell signaling pathways (AKT/AMPK) and significantly decreased protein expression levels of cleaved PARP, cytochrome c, LC3-II and p62. Also, rutin significantly increased protein expression levels of full-length caspase 3 in SH-SY5Y cells treated with MPP . Transmission electron microscope (TEM) images demonstrated a reduction in autophagosomes in rutin-pretreated SH-SY5Y cells exposed to $\mathrm{MPP}^{+}$. These results provide experimental support for rutin's neuroprotective activity against $\mathrm{MPP}^{+}$-induced toxicity in SH-SY5Y cells, which is as a promising therapeutic agent for clinical trials in humans.
\end{abstract}

Keywords Rutin $\cdot$ Apoptosis $\cdot$ Autophagy $\cdot$ Cell signaling $\cdot$ MPP

\section{Abbreviations \\ 6-OHDA 6-hydroxydopamine \\ ADP Adenosine diphosphate}

Highlights

- Rutin inhibits cell toxicity in SH-SY5Y cells treated with MPP

- Rutin protects against apoptosis in SH-SY5Y cells treated with $\mathrm{MPP}^{+}$

- Rutin rescues changes in nuclear morphology in SH-SY5Y cells treated with $\mathrm{MPP}^{+}$

- Rutin inhibits abnormal autophagy activation in SH-SY5Y cells treated with $\mathrm{MPP}^{+}$

- The protective effect of rutin against $\mathrm{MPP}^{+}$-induced toxicity involves the regulation of AKT/AMPK signaling

\section{Okobi Eko Ekpo}

oekpo@uwc.ac.za

1 Department of Medical Biosciences, University of the Western Cape, Robert Sobukwe Road, Private Bag X17, Bellville 7535, South Africa

2 Department of Anatomy, School of Basic Medical Sciences, University of Benin, Benin City, Edo State, Nigeria

3 Division of Molecular Biology and Human Genetics, Department of Biomedical Sciences, Faculty of Medicine and Health Sciences, Stellenbosch University, Cape Town, South Africa

$\begin{array}{ll}\text { AKT } & \text { Protein Kinase B } \\ \text { AMP } & \text { Adenosine Monophosphate } \\ \text { AMPK } & \begin{array}{l}\text { 5' adenosine monophosphate-activated } \\ \text { protein kinase }\end{array} \\ \text { ATP } & \text { Adenosine triphosphate } \\ \text { Ca }^{2+} & \text { Calcium } \\ \text { DMEM } & \text { Dulbecco's modified Eagle medium } \\ \text { FBS } & \text { Fetal bovine serum } \\ \text { LC3 } & \text { Light chain 3 } \\ \text { MPP } & \text { 1-methyl-4-phenylpyridinium } \\ \text { MTT } & \text { 3-(4,5-dimethylthiazol-2-yl)-2, } \\ & \text { 5-diphenyltetrazolium bromide } \\ \text { p62 } & \text { Ubiquitin-binding protein } \\ \text { PARP } & \text { Poly (ADP-ribose) polymerase } \\ \text { PBS } & \text { Phosphate buffered saline } \\ \text { PD } & \text { Parkinson's Disease } \\ \text { PI3K } & \text { Phosphatidylinositol 3-kinase } \\ \text { SEM } & \text { Standard error of the mean } \\ \text { SNpc } & \text { Substantia Nigra pars compacta } \\ \text { TEM } & \text { Transmission electron microscopy }\end{array}$

AKT

AMPK

ATP

$\mathrm{Ca}^{2+}$

FBS

LC3

MPP
Protein Kinase B

$5^{\prime}$ adenosine monophosphate-activated protein kinase

Calcium

Fetal bovine serum

Light chain 3

3-(4,5-dimethylthiazol-2-yl)-2,

5-diphenyltetrazolium bromide

Ubiquitin-binding protein

Phosphate buffered saline

Parkinson's Disease

Standard error of the mean

Transmission electron microscopy 


\section{Introduction}

Parkinson's Disease (PD) is the second most common neurodegenerative disorder following Alzheimer's disease (Reeve et al. 2014). Although the pathogenesis of PD is not entirely understood, aging, genetic susceptibility, inflammation and apoptosis have been implicated (Chiang et al. 2017; Enogieru et al. 2018a; Inamdar et al. 2007). There is also evidence suggesting that autophagy plays a critical role in the progression of PD (Nixon 2013; Pan et al. 2009). Therefore, a better understanding of the involvement of apoptosis and autophagy might help in the search for new and efficient treatment options for PD.

Apoptosis is a form of programmed cell death associated with PD pathophysiology (Erekat 2018; Venderova and Park 2012). Molecular findings linked to apoptosis have been previously described in post-mortem PD tissues, such as increased caspase- 3 activity in the Substantia Nigra pars compacta (SNpc) of the midbrain (Hartmann 2004). On the other hand, autophagy involves the degradation of cellular constituents in autophagolysosomes, initiated by sequestration of intracellular components in autophagosomes which is then fused with lysosomes (Yorimitsu and Klionsky 2005). Although autophagy removes long-lived proteins and impaired organelles, it can also act as a survival mechanism in stress conditions (White 2008). When autophagy is initiated incorrectly, and is extensive, it acts as a cell-death pathway (Ghavami et al. 2010; Maycotte and Thorburn 2011). Thus, autophagy can either maintain neuronal homeostasis or result in neuronal loss when extensively activated (Batlevi and La Spada 2011; Lee 2012).

Various intracellular signaling cascades exist in all eukaryotic cells playing vital roles in several cellular activities. For instance, the PI3K/AKT pathway controls cellular activities like neuronal cell proliferation, migration and plasticity (Amini-Khoei et al. 2019; Jha et al. 2015). Activation of the PI3K/AKT pathway encourages cell survival, although several mechanisms involving PI3K/AKT and their association with progressive neurodegeneration remains an area of active focus in PD research (Jha et al. 2015). AMPK is a sensor of AMP:ATP ratio facilitating adaptive measures in response to low energy conditions (Rosso et al. 2016). AMPK regulates the whole organism and is linked to neuronal proliferation and differentiation, synaptic connectivity, and neuroprotection (Rosso et al. 2016). Previous reports suggest that AMPK has a crucial role in the pathophysiology of PD owing to its activation during oxidative stress and autophagy conditions (Arsikin et al. 2012; Hardie 2007).

Bioactive compounds targeting the impaired AKT/AMPK balance could meaningfully contribute to neuroprotection in PD-challenged brains. One such compound is rutin, a flavonoid glycoside, abundant in buckwheat, vegetables and fruit (Enogieru et al. 2018b; Enogieru et al. 2018c). It has been studied for its numerous pharmacological properties such as antidepressant (Anjomshoa et al. 2020), anticarcinogenic (Perk et al. 2014), anti-inflammatory (Yoo et al. 2014) and cytoprotective effects (Magalingam et al. 2016). Concerning neuroprotection, rutin has been shown to protect against toxicity induced by 1-methyl-4-phenylpyridinium $\left(\mathrm{MPP}^{+}\right)$, 6hydroxydopamine (6-OHDA) and rotenone (Enogieru et al. 2019; Magalingam et al. 2013; Park et al. 2014). However, the activity of rutin on AKT/AMPK signaling and autophagy in a $\mathrm{MPP}^{+}$- induced model of PD has not been investigated. Accordingly, and for the first time, the present study investigated such activity. In addition, intracellular apoptotic activity was investigated using assay-based kits and flow cytometry, changes in nuclear morphology was demonstrated using Hoechst fluorescence staining, ultrastructural changes in morphology and autophagy was evaluated using the transmission electron microscope, and changes in protein expression levels of apoptotic, autophagic and cell signaling markers were studied in untreated and treated SH-SY5Y cells.

\section{Materials and methods}

\section{Cell culture and reagents}

SH-SY5Y neuroblastoma cells initially purchased from the American Type Culture Collection (ATCC, Rockville, MA), was provided by Dr. AM Serafin (Division of Radiobiology, Stellenbosch University, South Africa). SH-SY5Y cells were maintained in Dulbecco's modified Eagle medium (DMEM) (Life Technologies, USA), supplemented with 10\% Fetal bovine serum (FBS) (Life Technologies, USA) and $1 \%$ penicillinstreptomycin (Lonza, USA), at $37{ }^{\circ} \mathrm{C}, 5 \% \mathrm{CO}_{2}$ in a humidified incubator. In the cell culture experiments, fresh stock solutions of $\mathrm{MPP}^{+}$(purity $\geq 98 \%$ HPLC; Sigma Aldrich, St. Louis, MO, USA) were prepared in un-supplemented DMEM and used at a final concentration of $1 \mathrm{mM}$. Rutin $\left(\mathrm{C}_{27} \mathrm{H}_{30} \mathrm{O}_{16}\right.$; purity $\geq 94 \%$ HPLC) was purchased from Sigma-Aldrich (St. Louis, MO, USA) without further purification, and fresh stock solutions were prepared in dimethyl sulfoxide (DMSO, Life Technologies, USA) and diluted in culture media at final concentrations of $25 \mu \mathrm{M}, 50 \mu \mathrm{M}$ and $100 \mu \mathrm{M}$.

\section{Cell toxicity and viability assays}

The ApoTox-Glo ${ }^{\mathrm{TM}}$ Triplex Assay (Promega, USA) was utilized in this study to assess cytotoxicity and caspase activation actions. SH-SY5Y cells were seeded at a density of $5.0 \times 10^{3}$ /well in white-walled 96 well plates and were allowed to attach for $24 \mathrm{~h}$. Cells were pre-treated with complete culture media supplemented with $25 \mu \mathrm{M}, 50 \mu \mathrm{M}$ or $100 \mu \mathrm{M}$ of rutin for $4 \mathrm{~h}$ and then treated with $1 \mathrm{mM}$ of $\mathrm{MPP}^{+}$for a total of $48 \mathrm{~h}$. The concentration and duration for $\mathrm{MPP}^{+}$was selected to 
establish the in vitro PD model as previously reported (Enogieru et al. 2020; Kumar et al. 2013; Zhao et al. 2020). After treatment, toxicity experiments were performed according to manufacturer's instructions, and fluorescence was measured using the GloMax ${ }^{\mathrm{TM}}$ Multiscan plate reader (Promega, USA) at the wavelength sets of $490 \mathrm{Ex} / 510-570 \mathrm{Em}$.

The trypan blue dye exclusion test was used to evaluate the population of viable/live cells present in a cell suspension. In this assay, viable/live cells possessing intact cell membranes block entry of the dye and thus prevent cell staining (Strober 1997). SH-SY5Y cells were seeded at a density of $1.6 \times 10^{4}$ $/ \mathrm{cm}^{2}$ in $60 \mathrm{~mm}$ dishes and were allowed to attach for $24 \mathrm{~h}$. After that, supernatants were discarded, and cells were treated as described in section 2.2.1. Adherent cells were detached by trypsinization, pelleted, and resuspended in fresh media. A total of $10 \mu \mathrm{l}$ of cell suspension was added to an equivalent volume of $0.4 \%$ trypan blue dye (Sigma Aldrich, St. Louis, MO, USA) and loaded into a BioRad TC20 $0^{\mathrm{TM}}$ automated cell counter. Viability was expressed as the percentage of total cell count that were viable/live cells.

\section{Estimation of Caspase-3 activation and Caspase-9 activity}

After fluorescence reading from the cytotoxicity experiment using the ApoTox-Glo assay kit in section 2.2.1, estimation of caspase $3 / 7$ activation was performed according to the instructions of the manufacturer, and luminescence was measured using the GloMax ${ }^{\mathrm{TM}}$ Multiscan plate reader.

The ApoTarget ${ }^{\mathrm{TM}}$ Caspase-9 Protease Assay (Life Technologies, USA) was utilized in this study to measure caspase-9 proteolytic activity. SH-SY5Y cells were seeded at a density of $1.2 \times 10^{5} / \mathrm{ml}$ in 100-mm dishes and were allowed to attach for $24 \mathrm{~h}$. Following treatment with rutin and $\mathrm{MPP}^{+}$as described in section 2.2.1, measurements of caspase-9 activity were performed according to manufacturer's instructions, and absorbance was read using a Polarstar Omega plate reader (BMG Labtech, USA) at $405 \mathrm{~nm}$.

\section{Flow cytometric evaluation of apoptosis}

The FITC Annexin V/Dead cell apoptosis kit (Life Technologies, USA) was utilized in this study to assay for apoptosis. Upon cellular staining with FITC Annexin V and PI, apoptotic and dead cells fluoresce in green and red while viable cells do not fluoresce. SH-SY5Y cells were seeded at a density of $1.2 \times 10^{5} / \mathrm{ml}$ in $100 \mathrm{~mm}$ dishes and were allowed to attach for $24 \mathrm{~h}$. Following treatment with rutin and $\mathrm{MPP}^{+}$as described in section 2.2.1, experiments were performed according to the manufacturer's instructions. Stained cell suspensions were analyzed using a BD FACSCalibur flow cytometer (Becton Dickinson, Franklin Lakes, New Jersey, USA) to measure red and green fluorescence, with a total of
10,000 events collected for each sample. Fluorescence acquisition, compensation and data analysis were performed according to the manufacturer's instructions.

\section{Nuclear staining with Hoechst 33342}

Hoechst 33342 nucleic acid stain (Life Technologies, USA) was utilized in this study to demonstrate apoptotic cells. Briefly, cells were seeded at a density of $1.1 \times 10^{5} / \mathrm{ml}$ in $60 \mathrm{~mm}$ dishes and were allowed to attach for $24 \mathrm{~h}$. Following treatment with rutin and $\mathrm{MPP}^{+}$as described in section 2.2.1, experiments were performed according to the manufacturer's instructions and cells were viewed for fluorescent imaging using a Zeiss Axio-plan 2 fluorescent microscope (Zeiss, Germany).

\section{Western blot}

Western blots were used to evaluate the effects of rutin treatment on protein markers of apoptosis, autophagy and cell signaling. Following treatment with rutin and $\mathrm{MPP}^{+}$as described in section 2.2.1, proteins were prepared for blocking with the relevant primary antibody as previously reported by our laboratory (Enogieru et al. 2019). Primary antibodies included full-length caspase 3 (rabbit polyclonal, 1:1000, Cell Signalling Technology, USA). cleaved poly (ADP-ribose) polymerase (PARP; rabbit polyclonal, 1:1000, Cell Signalling Technology), LC3 (rabbit monoclonal, 1:2000, Cell Signalling Technology), SQSTM1/p62 (rabbit polyclonal, 1:1000, Cell Signalling Technology), phospho-Akt (rabbit monoclonal, 1:1000, Cell Signalling Technology), phosphoAMPK (rabbit monoclonal, 1:500, Cell Signalling Technology), loading control GAPDH (rabbit polyclonal, 1:1000; Santa Cruz Biotechnology, USA). Membranes were incubated with appropriate HRP-conjugated secondary antibodies (1:5000, Santa Cruz Biotechnology, USA) and visualized using a SuperSignal ${ }^{\circledR}$ West Pico Chemiluminescent kit (Thermo Scientific, USA). Image J software (http://imagej. nih.gov/ij/) was utilized to quantify western blots by means of densitometric measurements.

\section{Transmission electron microscopy}

SH-SY5Y cells were seeded at a density of $1.2 \times 10^{5} / \mathrm{ml}$ in $100 \mathrm{~mm}$ dishes and were allowed to attach for $24 \mathrm{~h}$. Following treatment with rutin and $\mathrm{MPP}^{+}$as described in section 2.2.1, cells were centrifuged in ice-cold PBS at $3000 \mathrm{rpm}$ for $5 \mathrm{~min}$, fixed in $500 \mu \mathrm{L}$ of $2.5 \%$ phosphate-buffered glutaraldehyde and post-fixed in $1 \%$ osmium tetroxide in the same buffer. The fixed samples were subsequently processed for transmission electron microscopy. A Reichert ultramicrotome (SMM Instruments, Johannesburg, South Africa) with a diamond knife (Agar Scientific, Randburg, South Africa) was used 
to make silver to gold sections. Thin sections on copper grids were examined using a Jeol JEM 1011 transmission electron microscope at $80 \mathrm{kV}$ (Advanced Laboratory Solutions, Johannesburg, South Africa). Electron micrographs were produced with a Mega View III digital camera fitted onto the microscope and by means of the ITEM software package (Advanced Laboratory Solutions, Johannesburg, South Africa).

\section{Statistical analysis}

GraphPad Prism Software V7 was used for all statistical analyses (www.graphpad.com/scientific-software/prism/). Data are expressed as mean with standard error of mean (SEM). One-way analysis of variance (ANOVA) followed by Tukey's multiple comparisons post-hoc test was performed to determine statistical significance $(p<0.05)$.

\section{Results}

\section{Rutin inhibits cell toxicity in MPP ${ }^{+}$treated SH-SY5Y cells}

To assess the protective activity of rutin on $\mathrm{MPP}^{+}$induced SH-SY5Y cell toxicity, cells were pretreated with three concentrations of rutin $(25,50$ and $100 \mu \mathrm{M})$ before being exposed to $1 \mathrm{mM} \mathrm{MPP}^{+}$as described earlier. Our results revealed that treatment of SH-SY5Y cells with $\mathrm{MPP}^{+}$resulted in a significant increase $(p<0.0001$, Fig. 1a) in cell toxicity; however, pretreatment of SH-SY5Y cells with rutin significantly reduced toxicity at concentrations of $25 \mu \mathrm{M}(p=0.0016)$; $50 \mu \mathrm{M}(p=0.0025)$ and $100 \mu \mathrm{M}(p=0.0001)$ respectively. Similarly, all concentrations of rutin significantly increased ( $p<0.0001$, Fig. $1 b)$ cell viability when compared to cells treated with $\mathrm{MPP}^{+}$only.

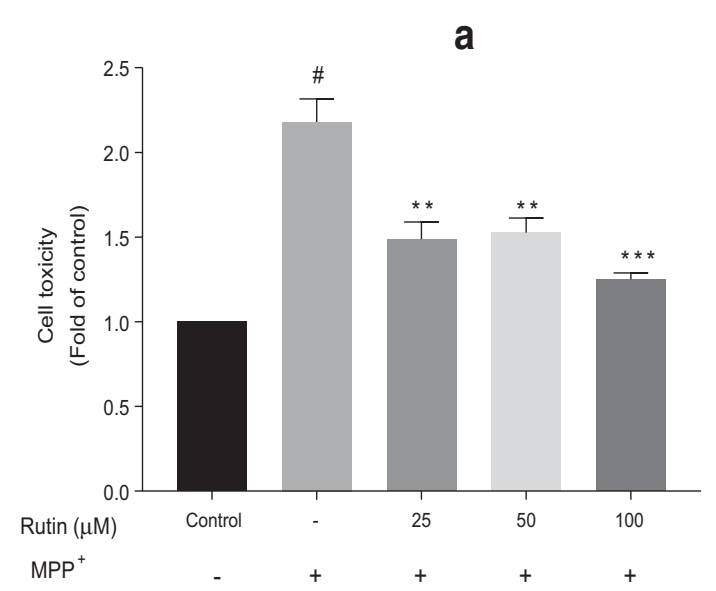

Rutin inhibits caspase-3/7 activation and attenuates
caspase- 9 activity in SH-SY5Y cells treated with MPP

To establish whether the effector caspase- $3 / 7$ are initiated in this model of PD, caspase- $3 / 7$ activation was investigated in treated and control SH-SY5Y cells. Findings show that whereas treatment with $\mathrm{MPP}^{+}$significantly increased $(\mathrm{p}<0.0001$, Fig. 2a) caspase $3 / 7$ activation, all concentrations of rutin significantly reduced $(p<0.0001)$ caspase $3 / 7$ activation. Next, the activity of caspase 9 was investigated in treated and control SH-SY5Y cells. Our findings reveal a significant increase $(p<0.0001$, Fig. 2b) in the activity of caspase 9 in cells treated with $\mathrm{MPP}^{+}$only, however, pretreatment with rutin resulted in a significant decrease in the activity of caspase 9 at concentrations of $25 \mu \mathrm{M}(p=0.0060) ; 50 \mu \mathrm{M}(p=0.0044)$ and $100 \mu \mathrm{M}(p=0.0006)$ respectively.

\section{Rutin inhibits apoptosis in MPP ${ }^{+}$treated SH-SY5Y cells detected by flow cytometry}

A flow cytometric analysis was performed to evaluate apoptotic activity in control and treated SH-SY5Y cells. Figure 3. shows a demonstration of PI versus V-FITC fluorescence. The lower left quadrant signifies the live cells and the lower right quadrant signifies the early apoptotic cells. The upper right quadrant signifies the late apoptotic cells while the upper left quadrant signifies the necrotic cells. Findings show that in the control SHSY5Y cells, $13.53 \%$ of cells were bound to annexin V-FITC, indicating low apoptotic activity. In cells treated with $\mathrm{MPP}^{+}$only, $44.81 \%$ of the cells bound to annexin V-FITC indicating a significant increase $(p<0.0001)$ in apoptotic activity. Conversely, following rutin pretreatment in SH-SY5Y cells, it was observed that significantly fewer cells bound to annexin V-FITC at concentrations of $25 \mu \mathrm{M}(32.95 \%, p=0.0066) ; 50 \mu \mathrm{M}(27.63 \%$, $p=0.0004)$ and $100 \mu \mathrm{M}(22.38 \%, \mathrm{p}<0.0001)$.

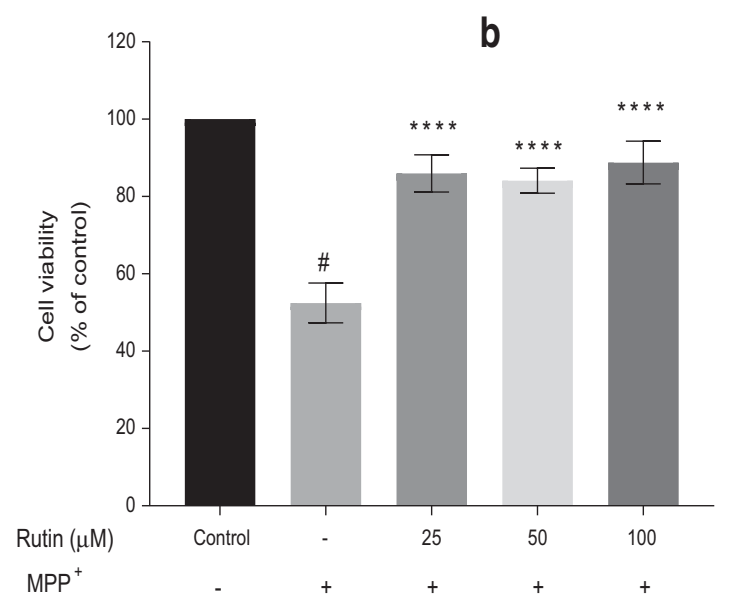

Fig. 1 Cell toxicity (a) and viability (b) in treated and control SH-SY5Y cells. Bars represent the mean \pm SEM from three separate experiments. ${ }^{\#} P<0.0001$ vs control SH-SY5Y cells; $* * P<0.005$, ***P $P 0.0005$ and $* * * * \mathrm{P}<0.0001$ vs SH-SY5Y cells treated with MPP ${ }^{+}$only 

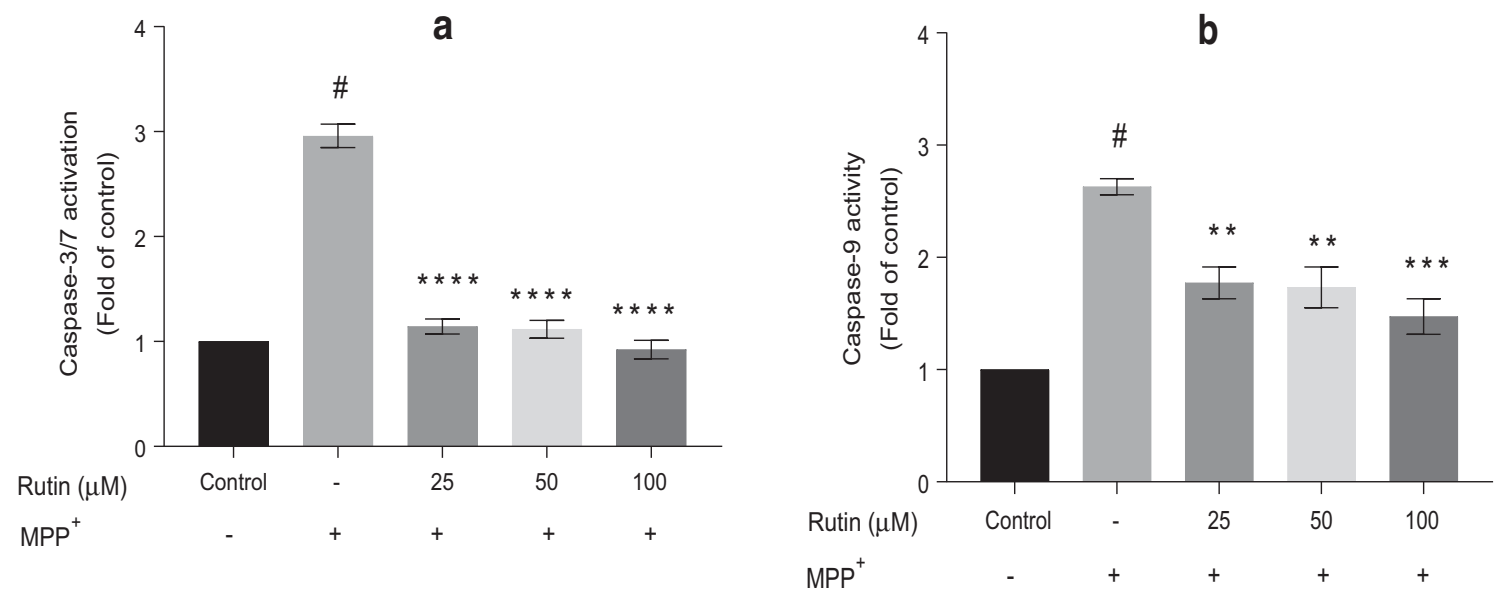

Fig. 2 Caspase-3/7 activation (a) and Caspase-9 activity (b) in treated and control SH-SY5Y cells. Bars represent the mean \pm SEM from three separate experiments. ${ }^{\#} \mathrm{P}<0.0001$ vs control SH-SY 5Y cells; $* * \mathrm{P}<0.005$, *** $\mathrm{P}<0.0005$ and $* * * * \mathrm{P}<0.0001$ vs SH-SY5Y cells treated with MPP ${ }^{+}$only

\section{Nuclear morphology in control and treated SH-SY5Y cells}

Changes in nuclear morphology were investigated using Hoechst 33342 staining. Obtained images showed that nuclei of control SH-SY5Y cells displayed a normal oval shape, while nuclei of cells treated with $\mathrm{MPP}^{+}$displayed features of apoptosis typically characterized by nuclear fragmentation and condensation. On the other hand, the SH-SY5Y cells pretreated with rutin did not display these apoptotic features (Fig. 4).

\section{Rutin inhibits $\mathrm{MPP}^{+}$triggered reduction of full-length caspase 3 and activation of cleaved PARP}

Western blots were used to detect protein expression levels of full-length caspase 3 and results obtained showed that treatment of SH-SY5Y cells with $\mathrm{MPP}^{+}$alone resulted in a

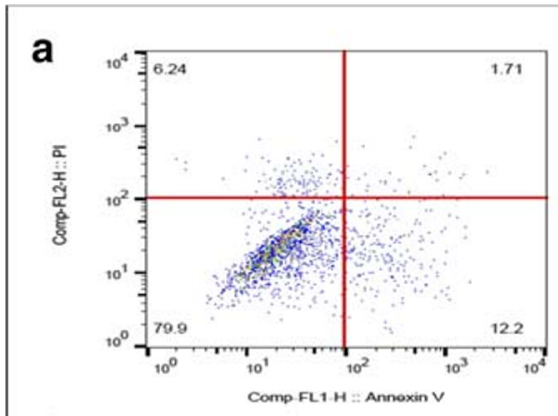

d

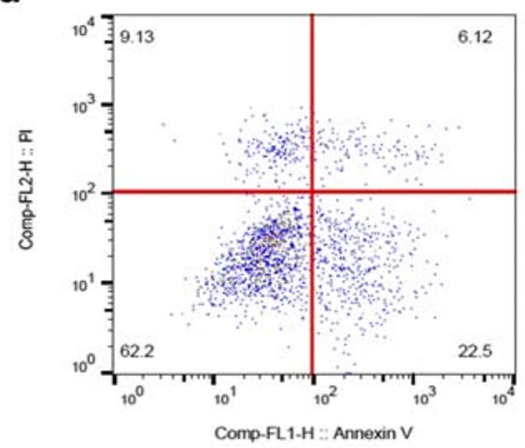

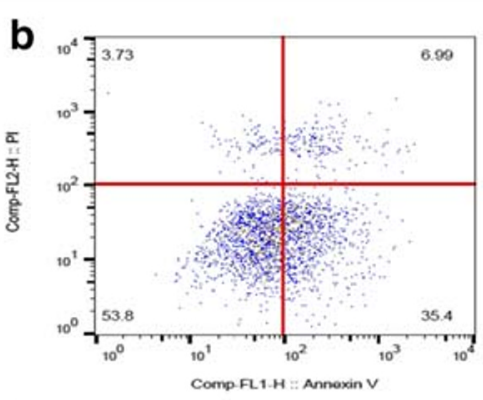

e

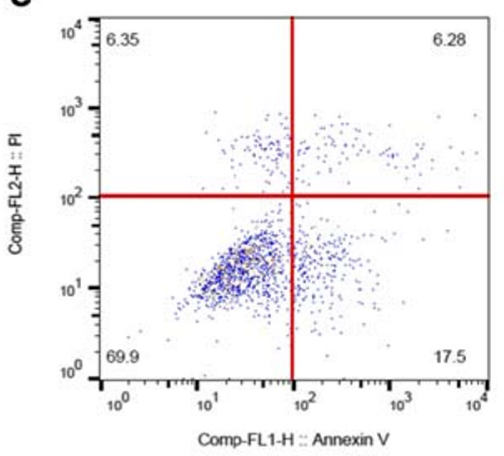

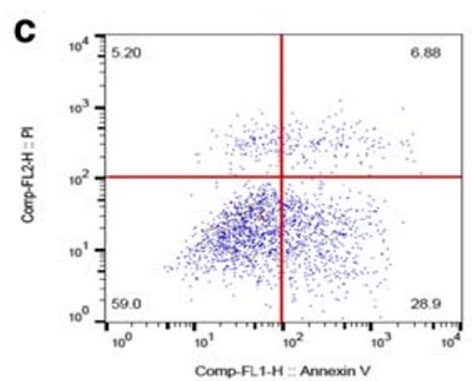

f

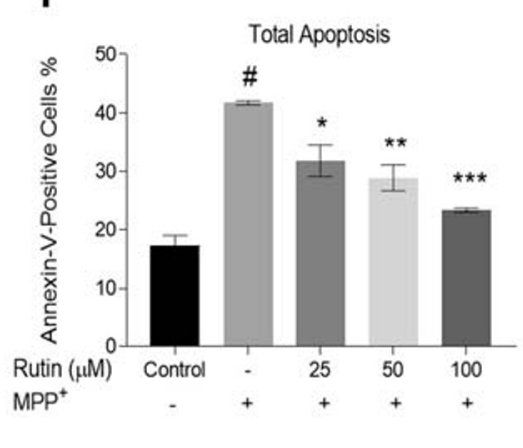

Fig. 3 Representative flow cytometric dot plots showing the effect of rutin on $\mathrm{MPP}^{+}$-induced apoptosis. (a). Control SH-SY5Y cells (b) SHSY5Y cells treated with $\mathrm{MPP}^{+}$only (c) SH-SY5Y cells treated with $25 \mu \mathrm{M}$ rutin and then treated with $\mathrm{MPP}^{+}$(d) SH-SY5Y cells treated with $50 \mu \mathrm{M}$ rutin and then treated with $\mathrm{MPP}^{+}$(e) SH-SY5Y cells treated with
$100 \mu \mathrm{M}$ rutin and then treated with $\mathrm{MPP}^{+}$(f) Graph showing the total apoptotic activity in control and treated SH-SY5Y cells. Bars represent the mean \pm SEM from three separate experiments. ${ }^{\#} P<0.0001$ vs control SH-SY5Y cells; $* P<0.05, * * P<0.005$ and $* * * P<0.0005$ vs SH-SY5Y cells treated with $\mathrm{MPP}^{+}$only 


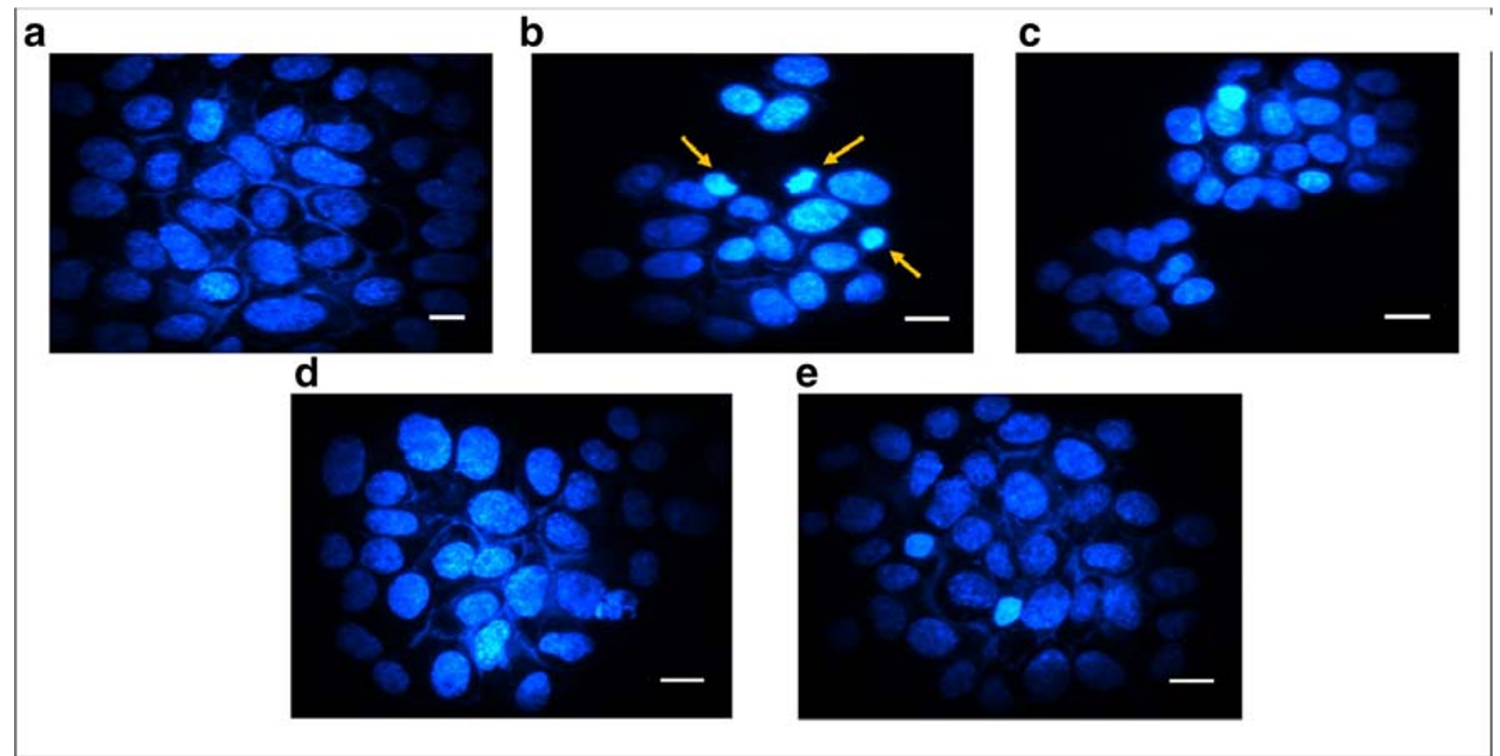

Fig. 4 Fluorescence micrographs of Hoechst 33342 stained nuclear morphology. (a) Control SH-SY5Y cells (b) SH-SY5Y cells treated with $\mathrm{MPP}^{+}$only (c) SH-SY5Y cells pretreated with $25 \mu \mathrm{M}$ rutin and then treated with $\mathrm{MPP}^{+}$(d) SH-SY5Y cells pretreated with $50 \mu \mathrm{M}$ rutin and

significant decrease in the expression of full-length caspase 3 ( $p=0.0005$, Fig. 5a). Following pretreatment of SH-SY5Y cells with rutin, the expression levels of full-length caspase 3 were significantly increased at concentrations of $25 \mu \mathrm{M}(p=$ $0.0205) ; 50 \mu \mathrm{M}(p=0.0051)$ and $100 \mu \mathrm{M}(p=0.0026)$ respectively. The decrease in the full-length caspase 3 appears to confirm the previous results on the activation of caspase 3/7 in SH-SY5Y cells treated with $\mathrm{MPP}^{+}$only. Conversely, the increase in the expression levels of full-length caspase 3 following rutin pretreatment could also be confirmation of the

a

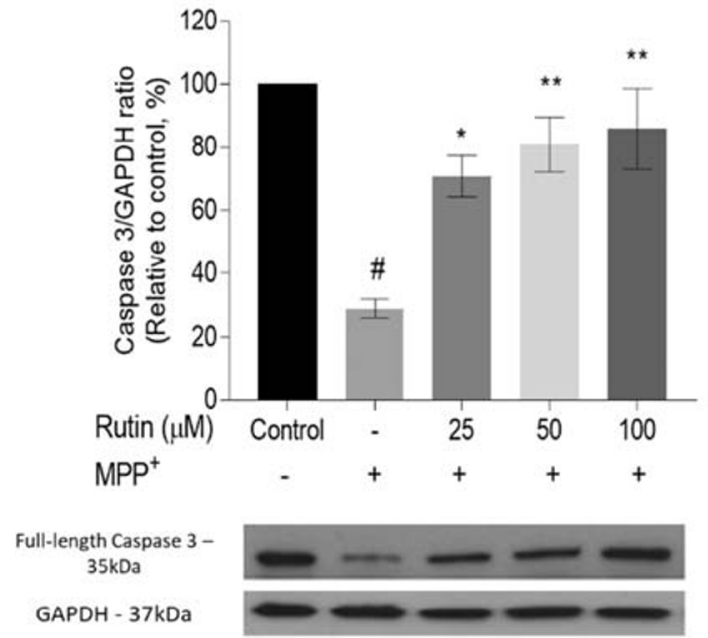

Fig. 5 Rutin prevents $\mathrm{MPP}^{+}$induced apoptosis in SH-SY5Y cells. (a) Protein expression of full-length caspase-3 following treatment (b) Protein expression of cleaved PARP following treatment. Data is presented as the ratio of the target protein and GAPDH loading control. Bars then treated with $\mathrm{MPP}^{+}$(E) SH-SY5Y cells pretreated with $100 \mu \mathrm{M}$ and then treated with $\mathrm{MPP}^{+}$. Arrows indicate apoptotic cells. Scale bar indicates $100 \mu \mathrm{M}$

previous results on the ability of rutin to inhibit caspase 3 activity in $\mathrm{MPP}^{+}$treated SH-SY5Y cells.

Next, to determine whether the effector caspases activate PARP, western blots were utilized to detect expression levels of cleaved PARP. Following quantification of western blot images, treatment of SH-SY5Y cells with $\mathrm{MPP}^{+}$only resulted in a significant increase in the expression of cleaved PARP $(p<0.0001$, Fig. $5 b)$, thus indicating increased apoptosis in these cells. Conversely, when the cells were pretreated with all concentrations of rutin, a significant reduction in the

\section{b}

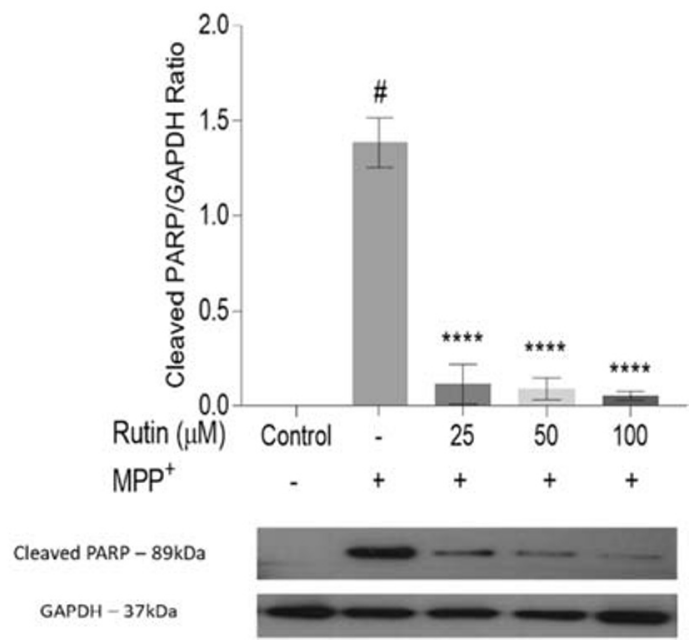

represent the mean relative band intensity \pm SEM for three separate experiments. ${ }^{\#} P<0.0001$ vs control cells; $* P<0.05$, $* * P<0.005$ and $* * * * \mathrm{P}<0.0001$ vs cells treated with $\mathrm{MPP}^{+}$only 
expression levels of cleaved PARP $(\mathrm{p}<0.0001)$ was observed, suggesting decreased apoptosis and also confirming the previous finding that rutin inhibits $\mathrm{MPP}^{+}$-induced apoptosis in SH-SY5Y cells.

\section{Rutin inhibits abnormal autophagy activation in SH- SY5Y cells treated with MPP ${ }^{+}$}

Western blots were used to detect expression levels of autophagosome-linked LC3-II, a widely used marker of autophagy (Kabeya et al. 2000). Findings revealed that treatment of SH-SY5Y cells with MPP ${ }^{+}$resulted in a significant increase in the expression levels of LC3-II ( $p<0.0001$, Fig. 6a). Autophagic activity was significantly reduced in rutin pretreated SH-SY5Y cells at concentrations of $25 \mu \mathrm{M}(p=$ $0.0473) ; 50 \mu \mathrm{M}(p=0.0320)$ and $100 \mu \mathrm{M}(p=0.0092)$ respectively.

p62 is an autophagy marker known to link ubiquitinated proteins to LC3 for degradation via autophagy (Pankiv et al. 2007). p62 is an important indicator of autophagy because its accumulation is unusually elevated when there is a block or defect in the activation of autophagy (Lynch-Day et al. 2012). Treatment of SH-SY5Y cells with $\mathrm{MPP}^{+}$only resulted in a significant increase in the expression of $\mathrm{p} 62$ in SH-SY5Y cells ( $p=0.0001$, Fig. 6b). However, p62 activity was significantly reduced in rutin pretreated SH-SY5Y cells at concentrations of $25 \mu \mathrm{M}(p=0.0050) ; 50 \mu \mathrm{M}(p=0.0055)$ and $100 \mu \mathrm{M}(p=$ 0.0083 ) respectively.

\section{TEM evaluation of control and treated SH-SY5Y cells}

To further verify the findings from western blots in section 3.6, transmission electron microscopy (TEM) was utilized to examine autophagy and ultrastructural changes in the

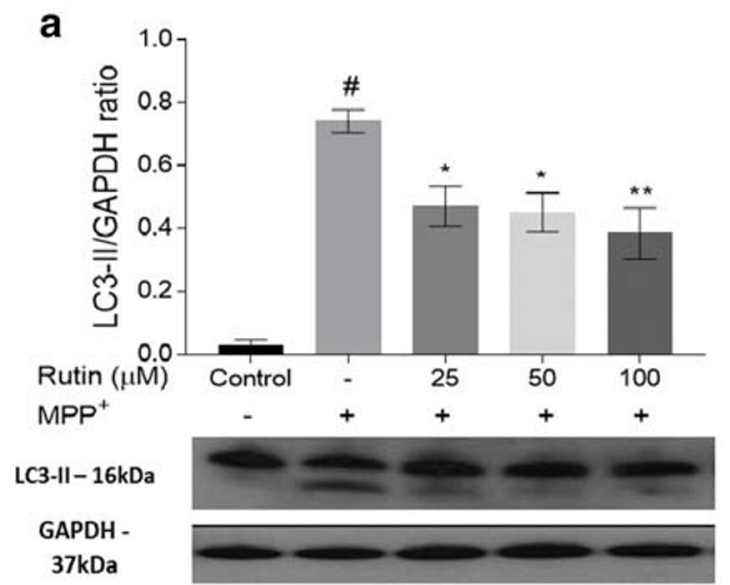

Fig. 6 Rutin prevents MPP ${ }^{+}$induced aberrant activation of autophagy in SH-SY5Y cells. (a) Protein expression of LC3-II following treatment (b) Protein expression of p62 following treatment. Data is presented as the ratio of the target protein and GAPDH loading control. Bars represent the morphology of control and treated SH-SY5Y cells. TEM images revealed the presence of autophagy in treated SH-SY5Y cells (Fig. 7). Cells treated with $\mathrm{MPP}^{+}$only contained numerous autophagic vacuoles (with more visible autophagosomes), showed distorted mitochondria structure, mitochondrial swelling and rupturing cristae in the electron micrographs. The general ultrastructure in rutin pretreated SH-SY5Y cells showed markedly improved mitochondrial architecture, as well as fewer autophagosomes when compared to the SHSY5Y cells treated with $\mathrm{MPP}^{+}$only.

\section{Rutin regulates the AKT/AMPK signaling pathways in SH-SY5Y cells treated with MPP ${ }^{+}$}

Earlier studies have established that AKT mediates prosurvival effects when cells are exposed to various apoptotic stimuli (Kim and Park 2018; Zhao et al. 2016). Findings revealed that treatment of SH-SY5Y cells with $\mathrm{MPP}^{+}$only resulted in a significant decrease $(p=0.0028$, Fig. 8a) in the expression of $\mathrm{p}-\mathrm{AKT}$, thus indicating that there was downregulation of pro-survival signaling. Conversely, following pretreatment of SH-SY5Y cells with rutin, a significant increase in the expression of $\mathrm{p}$-AKT was observed at concentrations of $25 \mu \mathrm{M}(p=0.0283), 50 \mu \mathrm{M}(p=0.0400)$ and $100 \mu \mathrm{M}(p=$ 0.0002 ) respectively, possibly indicating an upregulation of pro-survival signaling in $\mathrm{MPP}^{+}$-treated SH-SY5Y cells. This could be linked to the potential neuroprotective effects of rutin against $\mathrm{MPP}^{+}$induced apoptosis and cell death.

AMPK is a molecular measure of energy status and becomes activated during oxidative stress, autophagy and other conditions that lead to the depletion of cellular energy ( Ju et al. 2014; Wen et al. 2018). Findings revealed that treatment of SH-SY5Y cells with $\mathrm{MPP}^{+}$only resulted in a significant increase in the expression of pAMPK $\alpha(p=0.0004$, Fig. 8b).

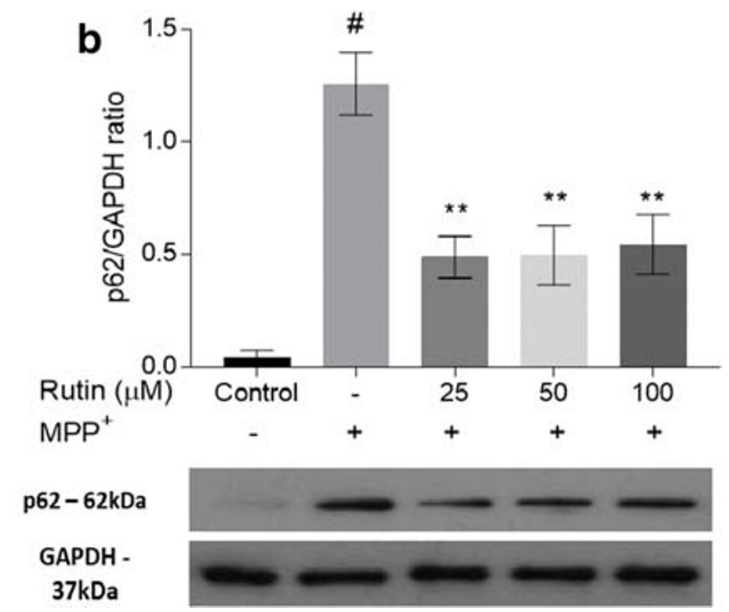

mean relative band intensity \pm SEM for three separate experiments. ${ }^{\#} P<0.0001$ vs control cells; $* P<0.05$, and $* * P<0.005$ vs cells treated with $\mathrm{MPP}^{+}$only 

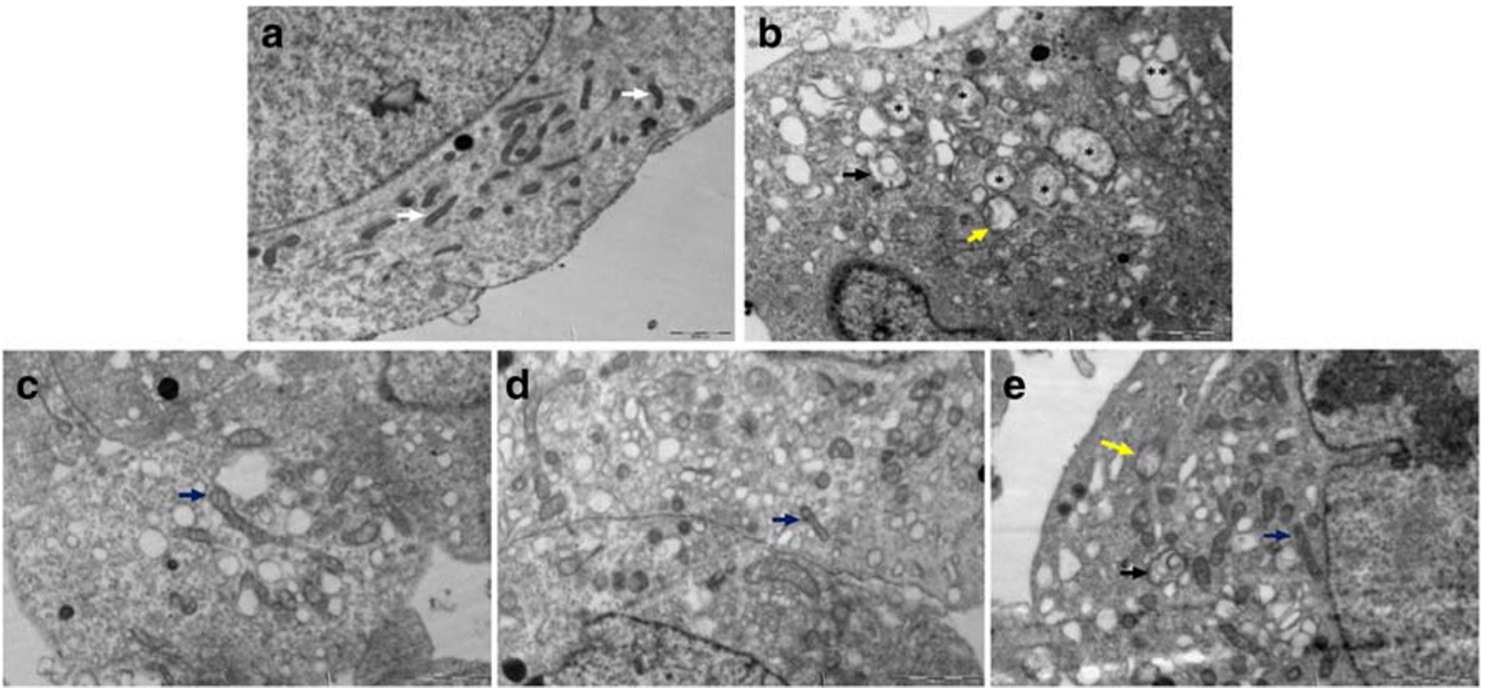

Fig. 7 TEM images showing inhibition of $\mathrm{MPP}^{+}$induced aberrant autophagy and mitochondrial changes in SH-SY5Y cells pretreated with rutin. (a) Control SH-SY5Y cells (b) SH-SY5Y cells treated with $\mathrm{MPP}^{+}$ only (c) SH-SY5Y cells pretreated with $25 \mu \mathrm{M}$ and then treated with $\mathrm{MPP}^{+}$(d) SH-SY5Y cells pretreated with $50 \mu \mathrm{M}$ and then treated with $\mathrm{MPP}^{+}$(e) SH-SY5Y cells pretreated with $100 \mu \mathrm{M}$ and then treated with

Following pretreatment of SH-SY5Y cells with rutin, a significant reduction in the expression of $\mathrm{pAMPK} \alpha$ was observed at concentrations of $25 \mu \mathrm{M}(p=0.0040) ; 50 \mu \mathrm{M}(p=0.0193)$ and $100 \mu \mathrm{M}(p=0.0007)$ respectively. These findings indicate that rutin was able to inhibit $\mathrm{MPP}^{+}$-induced activation of AMPK in SH-SY5Y cells.

\section{Discussion}

The present study provides new evidence of the neuroprotective activity of rutin through its inhibition of apoptosis and

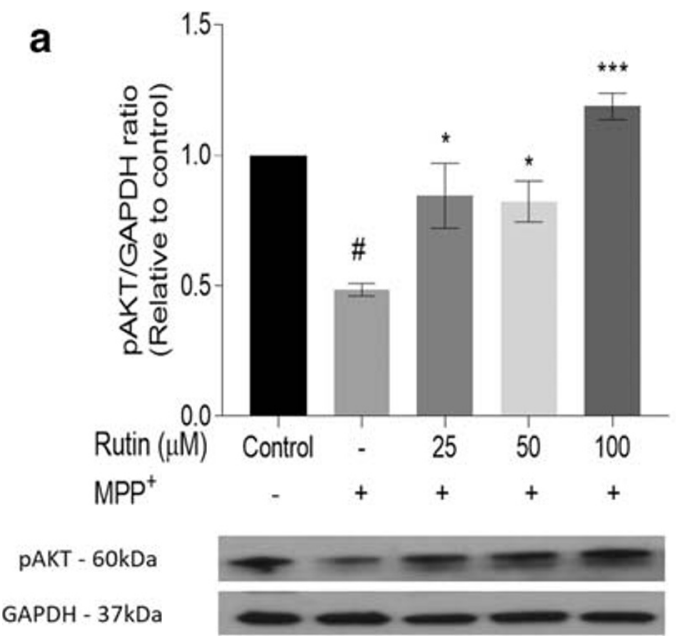

Fig. 8 Rutin regulates signaling pathways in SH-SY5Y cells. (a) Protein expression of $\mathrm{p}$-AKT following treatment (b) Protein expression of pAMPK $\alpha$ following treatment. Data is presented as the ratio of the target protein and GAPDH loading control. Bars represent the mean relative
$\mathrm{MPP}^{+}$. White arrows indicate healthy mitochondria; black arrows show different autophagic vacuoles: * represents autophagosomes (with cytoplasm); ** represents autophagolysosomes at the late stage of degradation. Yellow arrows indicate swollen or degrading mitochondria with distorted or disorganized cristae; blue arrows indicate improved mitochondria structure. Scale bar represents $2 \mu \mathrm{M}$

regulation of AKT/AMPK signaling as well as autophagy in a $\mathrm{MPP}^{+}$-induced PD model. It is reported that apoptosis is a consequence of activated caspase proteolysis (Serviddio et al. 2011). Caspase-dependent and caspase-independent mechanisms have been proposed as essential mechanisms leading to dopaminergic neuronal death in the SNpc of PD patients (Schulz 2006). PARP enzymes are involved in neurodegenerative disorders, including PD (Martire et al. 2015). PARP, a downstream target of caspase-3, is a ubiquitous nuclear enzyme involved in DNA repair; however, when PARP levels are incredibly high, cell death is initiated (Bürkle 2001; Le et al. 2002). During cell death processes, PARP is cleaved into

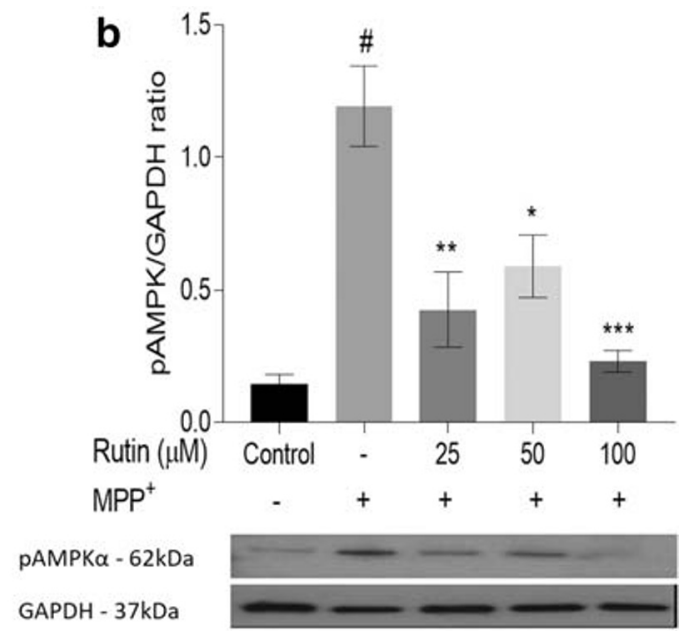

band intensity \pm SEM for three separate experiments. ${ }^{\#} P<0.0001$ vs control cells; $* P<0.05$, $* * P<0.005$ and $* * * P<0.0005$ vs cells treated with $\mathrm{MPP}^{+}$only 
fragments that are specific to various apoptotic signals. The action of caspase 3/7 activation most likely produced the 89$\mathrm{kDa}$ fragment detected in this study, which is in line with previous reports showing detection of PARP (Kumar et al. 2013; Lu et al. 2017). Different neuroprotective compounds studied in various PD models have demonstrated their ability to affect the expression of caspases and PARP. For example, in PC12 cells, curcumin was reported to inhibit PARP activation (Raza et al. 2008) and protect against $\mathrm{MPP}^{+}$-induced apoptosis (Chen et al. 2006). The polyphenol hesperidin was also found to reduce caspase-3/9 activities in an in vitro human SK-N-SH cellular model of rotenone-induced PD (Tamilselvam et al. 2013). Findings from this study show that rutin attenuates $\mathrm{MPP}^{+}$induced neuronal apoptotic death, at least in part, by down-regulating apoptotic signals such as caspase 3/7, caspase 9 and cleaved PARP.

Compelling evidence obtained from PD patients and PD models have helped to unravel the involvement of autophagy in PD pathogenesis (Cheung and Ip 2011). Reports reveal the accumulation of autophagic vacuoles in post-mortem brain tissues of PD patients (Hou et al. 2020; Zhang et al. 2012), and significant activation of the autophagy response has been subsequently detected in blood samples from PD patients (Prigione et al. 2010). Thus, there is growing interest in autophagic deregulation observed in PD since the autophagic pathway is responsible for the clearance of aberrant proteins. Many of the neurotoxins used to induce PD also influence the autophagy pathway, for example, $\mathrm{MPP}^{+}$causes increased autophagy in SH-SY5Y cells (Zhu et al. 2007). Reports show that the SNpc of mice treated with MPTP (1-methyl-4-phenyl1,2,3,6-tetrahydropyridine) exhibit autophagic cell death (Liu et al. 2013a; Meredith et al. 2009). While it is agreed that deficient autophagy activation would impede clearance of protein aggregates, it is suggested that the magnitude of autophagy produced may determine cell survival, with low levels linked to homeostatic functions and high levels stimulating cell death, either directly or indirectly (Wang et al. 2009). In line with previous reports (Liu et al. 2013b), we observe that $\mathrm{MPP}^{+}$causes aberrant/extreme activation of autophagy in SH-SY5Y cells. This may be due to excessive autophagic demand in the cells, which could not be balanced by cellular reserves, thus resulting in cell death. Also, $\mathrm{MPP}^{+}$ may have impaired the membrane integrity of lysosomes leading to protease leakage that caused damage to other cellular components (Button et al. 2015). A deficit in lysosomal function is known to stimulate autophagy, thereby leading to a pathological accumulation of autophagosomes that cannot be successfully cleared (Gomez-Suaga et al. 2011). In line with previous reports (Anglade et al. 1997; Zhu et al. 2003), our TEM images revealed abnormal accumulation of autophagosomes in SH-SY5Y cells treated with MPP ${ }^{+}$only. This is in sharp contrast to the infrequent detection of autophagosomes in control and rutin pretreated SH-SY5Y cells, probably due to the efficient and speedy clearance of autophagic vacuoles. The presence of elevated autophagosomes in our PD model besides signifying a flaw in the activation of autophagy might be as a result of a defective clearance which led to its accumulation. This is demonstrated by the increased expression of both LC3-II and p62 proteins in SH-SY5Y cells treated with $\mathrm{MPP}^{+}$only. The attenuation of abnormal autophagy activation by rutin provides the first evidence of its beneficial role in autophagy-related mechanism in a $\mathrm{MPP}^{+}$model of PD.

Findings from this study show that rutin pre-treatment prevents $\mathrm{MPP}^{+}$-induced toxicity partly through the regulation of the AKT signaling pathway. Once activated, the AKT pathway controls downstream signaling cascades that affect a variety of cellular activities including proliferation, survival, migration, differentiation, metabolism and polarity in different cell types including neurons (Greene et al. 2011; Manning and Cantley 2007; Zhang et al. 2016). Some reports support compromised AKT signaling in PD. For example, immunostaining of post-mortem brains reveals that AKT phosphorylation is significantly reduced in the dopaminergic SNpc of PD patients when compared with non-PD patients (Timmons et al. 2009). In other studies, AKT phosphorylation was significantly diminished by treatment of neuronal cells with PD neurotoxins (Malagelada et al. 2008; Rodriguez-Blanco et al. 2008; Tasaki et al. 2010), and treatments that inhibit loss of AKT phosphorylation are protective in such PD models (Malagelada et al. 2010; Tasaki et al. 2010). Some bioactive compounds exhibit their neuroprotective properties through their ability to activate the AKT pathway in various in vitro models of PD (Fukui et al. 2010; Qin et al. 2011; Tasaki et al. 2010). These reports suggest that most neuroprotective PD agents share a common characteristic in their ability to improve AKT activation. Accordingly, our findings show that $\mathrm{MPP}^{+}$treatment caused a reduction in phosphorylated AKT levels in SH-SY5Y cells while rutin pre-treatment upregulated phosphorylated AKT expression and thus inhibited downstream cellular activities associated with $\mathrm{MPP}^{+}$toxicity.

AMPK is considered a key regulator of cellular energy metabolism (Garcia and Shaw 2017). Activation of AMPK is regulated by $\mathrm{ROS}, \mathrm{Ca}^{2+}$ and cellular AMP/ATP ratio (Jung et al. 2008; Park et al. 2006), and has a range of effects that may be relevant to PD such as mitochondrial quality control, changes in cellular metabolism, promotion of autophagy, reduced inflammation and improved antioxidant capacity (Choi et al. 2010). Conversely, reports show that AMPK also plays a role in facilitating progragmmed cell death, particularly in situations of bioenergetic failure or severe cellular stress. Previous studies show that activation of AMPK by PDinducing neurotoxins promotes neuronal death by facilitating excessive autophagy and impaired protein synthesis (Xilouri and Stefanis 2011; Xu et al. 2014). Findings from this study agree with previous reports (Button et al. 2015; Gomez-Suaga 
et al. 2011; Xu et al. 2014) demonstrating that activation of AMPK stimulates autophagy and leads to accumulation of autophagosomes that cannot be successfully cleared.

In conclusion, this study provides new evidence that rutin attenuates the inhibition of AKT and activation of AMPK in a $\mathrm{MPP}^{+}$model of PD. This supports suggestions that a crosstalk between these signaling pathways leads to the debilitating effects of $\mathrm{MPP}^{+}$(Pan et al. 2009; Xu et al. 2014). Future studies will involve investigating the regulatory activity of rutin on autophagy and the AKT/AMPK signaling pathway in MPTP animal models of PD.

Acknowledgements We are grateful to the Parkinson's Disease Research Group, Division of Molecular Biology and Human Genetics, Stellenbosch University for providing some laboratory materials and workspace needed for this study.

Author contributions ABE performed cell culture experiments and analyzed the data. WH assisted with the western blot experiments. DCH and OEE developed the concepts, designed, and supervised the project. All authors have read and approved the final manuscript.

Funding This work did not receive any funding.

\section{Compliance with ethical standards}

Conflict of interest The authors declare that they have no conflict of interest.

Ethical approval This article does not contain any studies with human participants or animals performed by any of the authors.

Informed consent Not applicable. This article does not contain any studies with human participants.

\section{References}

Amini-Khoei H, Saghaei E, Mobini G-R, Sabzevary-Ghahfarokhi M, Ahmadi R, Bagheri N, Mokhtari T (2019) Possible involvement of $\mathrm{PI} 3 \mathrm{~K} / \mathrm{AKT} / \mathrm{mTOR}$ signaling pathway in the protective effect of selegiline (deprenyl) against memory impairment following ischemia reperfusion in rat. Neuropeptides 77:101942

Anglade P, Vyas S, Javoy-Agid F, Herrero M, Michel P, Marquez J, Mouatt-Prigent A, Ruberg M, Hirsch E, Agid Y (1997) Apoptosis and autophagy in nigral neurons of patients with Parkinson's disease. Histol Histopathol 12:25-32

Anjomshoa M, Boroujeni SN, Ghasemi S, Lorigooini Z, Amiri A, Balalidehkordi S, Amini-khoei H (2020) Rutin via increase in the CA3 diameter of the Hippocampus exerted antidepressant-like effect in mouse model of maternal separation stress: possible involvement of NMDA receptors. Behav Neurol 2020:1-9

Arsikin K, Kravic-Stevovic T, Jovanovic M, Ristic B, Tovilovic G, Zogovic N, Bumbasirevic V, Trajkovic V, Harhaji-Trajkovic L (2012) Autophagy-dependent and-independent involvement of AMPactivated protein kinase in 6-hydroxydopamine toxicity to SH-SY5Y neuroblastoma cells. Biochim Biophys Acta 1822:1826-1836

Batlevi Y, La Spada AR (2011) Mitochondrial autophagy in neural function, neurodegenerative disease, neuron cell death, and aging. Neurobiol Dis 43:46-51
Bürkle A (2001) PARP-1: a regulator of genomic stability linked with mammalian longevity. Chembiochem 2:725-728

Button RW, Luo S, Rubinsztein DC (2015) Autophagic activity in neuronal cell death. Neurosci Bull 31:382-394

Chen J, Tang X, Zhi J, Cui Y, Yu H, Tang E, Sun S, Feng J, Chen P (2006) Curcumin protects PC12 cells against 1-methyl-4phenylpyridinium ion-induced apoptosis by bcl-2-mitochondriaROS-iNOS pathway. Apoptosis 11:943-953

Cheung ZH, Ip NY (2011) Autophagy deregulation in neurodegenerative diseases-recent advances and future perspectives. J Neurochem 118:317-325

Chiang P-L, Chen H-L, Lu C-H, Chen P-C, Chen M-H, Yang I-H, Tsai N-W, Lin W-C (2017) White matter damage and systemic inflammation in Parkinson's disease. BMC Neurosci 18:48

Choi J-S, Park C, Jeong J-W (2010) AMP-activated protein kinase is activated in Parkinson's disease models mediated by 1-methyl-4phenyl-1, 2, 3, 6-tetrahydropyridine. Biochem Biophys Res Commun 391:147-151

Enogieru A, Omoruyi S, Ekpo O (2018a) Antioxidant and apoptosisinhibition potential of Carpobrotus edulis in a model of parkinson's disease. J African Assoc Physiol Sci 6:126-135

Enogieru AB, Haylett W, Hiss DC, Bardien S, Ekpo OE (2018b) Rutin as a potent antioxidant: implications for neurodegenerative disorders. Oxidative Med Cell Longev 2018:1-17

Enogieru AB, Omoruyi SI, Hiss DC, Ekpo OE (2018c) Potential antiparkinsonian agents derived from south African medicinal plants. J Herbal Med 13:1-7

Enogieru AB, Haylett WL, Miller HC, van der Westhuizen FH, Hiss DC, Ekpo OE (2019) Attenuation of endoplasmic reticulum stress, impaired calcium homeostasis, and altered bioenergetic functions in MPP+-exposed SH-SY5Y cells pretreated with Rutin. Neurotox Res 36:764-776

Enogieru AB, Omoruyi SI, Ekpo OE (2020) Aqueous leaf extract of Sutherlandia frutescens attenuates ROS-induced apoptosis and loss of mitochondrial membrane potential in MPP+-treated SH-SY5Y cells. Trop J Pharm Res 19:549-555

Erekat NS (2018) Apoptosis and its role in Parkinson's disease. Exon Public:65-82

Fukui M, Choi HJ, Zhu BT (2010) Mechanism for the protective effect of resveratrol against oxidative stress-induced neuronal death. Free Radic Biol Med 49:800-813

Garcia D, Shaw RJ (2017) AMPK: mechanisms of cellular energy sensing and restoration of metabolic balance. Mol Cell 66:789-800

Ghavami S, Eshragi M, Ande SR, Chazin WJ, Klonisch T, Halayko AJ, Mcneill KD, Hashemi M, Kerkhoff C, Los M (2010) S100A8/A9 induces autophagy and apoptosis via ROS-mediated cross-talk between mitochondria and lysosomes that involves BNIP3. Cell Res 20:314-331

Gomez-Suaga P, Luzon-Toro B, Churamani D, Zhang L, Bloor-Young D, Patel S, Woodman PG, Churchill GC, Hilfiker S (2011) Leucinerich repeat kinase 2 regulates autophagy through a calciumdependent pathway involving NAADP. Hum Mol Genet 21:511525

Greene LA, Levy O, Malagelada C (2011) Akt as a victim, villain and potential hero in Parkinson's disease pathophysiology and treatment. Cell Mol Neurobiol 31:969-978

Hardie DG (2007) AMP-activated/SNF1 protein kinases: conserved guardians of cellular energy. Nat Rev Mol Cell Biol 8:774-785

Hartmann A (2004) Postmortem studies in Parkinson's disease. Dialogues Clin Neurosci 6:281

Hou X, Watzlawik JO, Fiesel FC, Springer W (2020) Autophagy in Parkinson's disease. J Mol Biol 432:2651-2672

Inamdar N, Arulmozhi D, Tandon A, Bodhankar S (2007) Parkinson's disease: genetics and beyond. Curr Neuropharmacol 5:99-113 
Jha SK, Jha NK, Kar R, Ambasta RK, Kumar P (2015) p38 MAPK and PI3K/AKT signalling cascades in Parkinson's disease. Int J Mol Cell Med 4:67

Ju T-C, Chen H-M, Chen Y-C, Chang C-P, Chang C, Chern Y (2014) AMPK- $\alpha 1$ functions downstream of oxidative stress to mediate neuronal atrophy in Huntington's disease. Biochimica et Biophysica Acta (BBA)-Mol Basis Dis 1842:1668-1680

Jung S-N, Yang WK, Kim J, Kim HS, Kim EJ, Yun H, Park H, Kim SS, Choe W, Kang I (2008) Reactive oxygen species stabilize hypoxiainducible factor-1 alpha protein and stimulate transcriptional activity via AMP-activated protein kinase in DU145 human prostate cancer cells. Carcinogenesis 29:713-721

Kabeya Y, Mizushima N, Ueno T, Yamamoto A, Kirisako T, Noda T, Kominami E, Ohsumi Y, Yoshimori T (2000) LC3, a mammalian homologue of yeast Apg8p, is localized in autophagosome membranes after processing. EMBO J 19:5720-5728

Kim C, Park S (2018) IGF-1 protects SH-SY5Y cells against MPP+induced apoptosis via PI3K/PDK-1/Akt pathway. Endocrine Connect 7:443-455

Kumar H, Kim I-S, More SV, Kim B-W, Bahk Y-Y, Choi D-K (2013) Gastrodin protects apoptotic dopaminergic neurons in a toxininduced Parkinson's disease model. Evid Based Complement Alterna Med 2013:1-13

Le DA, Wu Y, Huang Z, Matsushita K, Plesnila N, Augustinack JC, Hyman BT, Yuan J, Kuida K, Flavell RA (2002) Caspase activation and neuroprotection in caspase-3-deficient mice after in vivo cerebral ischemia and in vitro oxygen glucose deprivation. Proc Natl Acad Sci 99:15188-15193

Lee J-A (2012) Neuronal autophagy: a housekeeper or a fighter in neuronal cell survival? Exp Neurobiol 21:1-8

Liu K, Shi N, Sun Y, Zhang T, Sun X (2013a) Therapeutic effects of rapamycin on MPTP-induced parkinsonism in mice. Neurochem Res 38:201-207

Liu Y, Shoji-Kawata S, Sumpter RM, Wei Y, Ginet V, Zhang L, Posner B, Tran KA, Green DR, Xavier RJ (2013b) Autosis is a Na+, K+ATPase-regulated form of cell death triggered by autophagyinducing peptides, starvation, and hypoxia-ischemia. Proc Natl Acad Sci 110:20364-20371

Lu JY, Su P, Barber JE, Nash JE, Le AD, Liu F, Wong AH (2017) The neuroprotective effect of nicotine in Parkinson's disease models is associated with inhibiting PARP-1 and caspase-3 cleavage. PeerJ 5: e3933

Lynch-Day MA, Mao K, Wang K, Zhao M, Klionsky DJ (2012) The role of autophagy in Parkinson's disease. Cold Spring Harb Perspect Med 2:a009357

Magalingam KB, Radhakrishnan A, Haleagrahara N (2013) Rutin, a bioflavonoid antioxidant protects rat pheochromocytoma (PC-12) cells against 6-hydroxydopamine (6-OHDA)-induced neurotoxicity. Int J Mol Med 32:235-240

Magalingam KB, Radhakrishnan A, Haleagrahara N (2016) Protective effects of quercetin glycosides, rutin, and isoquercetrin against 6hydroxydopamine (6-OHDA)-induced neurotoxicity in rat pheochromocytoma (PC-12) cells. Int J Immunopathol Pharmacol 29: 30-39

Malagelada C, Jin ZH, Greene LA (2008) RTP801 is induced in Parkinson's disease and mediates neuron death by inhibiting Akt phosphorylation/activation. J Neurosci 28:14363-14371

Malagelada C, Jin ZH, Jackson-Lewis V, Przedborski S, Greene LA (2010) Rapamycin protects against neuron death in in vitro andIn vivo models of Parkinson's disease. J Neurosci 30:1166-1175

Manning BD, Cantley LC (2007) AKT/PKB signaling: navigating downstream. Cell 129:1261-1274

Martire S, Mosca L, d'Erme M (2015) PARP-1 involvement in neurodegeneration: a focus on Alzheimer's and Parkinson's diseases. Mech Ageing Dev 146:53-64
Maycotte P, Thorburn A (2011) Autophagy and cancer therapy. Cancer Biol Ther 11:127-137

Meredith G, Totterdell S, Beales M, Meshul C (2009) Impaired glutamate homeostasis and programmed cell death in a chronic MPTP mouse model of Parkinson's disease. Exp Neurol 219:334-340

Nixon RA (2013) The role of autophagy in neurodegenerative disease. Nat Med 19:983-997

Pan T, Rawal P, Wu Y, Xie W, Jankovic J, Le W (2009) Rapamycin protects against rotenone-induced apoptosis through autophagy induction. Neuroscience 164:541-551

Pankiv S, Clausen TH, Lamark T, Brech A, Bruun J-A, Outzen H, Øvervatn A, Bjørkøy G, Johansen T (2007) p62/SQSTM1 binds directly to Atg8/LC3 to facilitate degradation of ubiquitinated protein aggregates by autophagy. J Biol Chem 282:24131-24145

Park IJ, Hwang JT, Kim YM, Ha J, Park OJ (2006) Differential modulation of AMPK signaling pathways by low or high levels of exogenous reactive oxygen species in colon cancer cells. Ann N Y Acad Sci 1091:102-109

Park S-E, Sapkota K, Choi J-H, Kim M-K, Kim YH, Kim KM, Kim KJ, Oh H-N, Kim S-J, Kim S (2014) Rutin from Dendropanax morbifera Leveille protects human dopaminergic cells against rotenone induced cell injury through inhibiting JNK and p38 MAPK signaling. Neurochem Res 39:707-718

Perk AA, Shatynska-Mytsyk I, Gerçek YC, Boztaș K, Yazgan M, Fayyaz S, Farooqi AA (2014) Rutin mediated targeting of signaling machinery in cancer cells. Cancer Cell Int 14:124

Prigione A, Piazza F, Brighina L, Begni B, Galbussera A, DiFrancesco JC, Andreoni S, Piolti R, Ferrarese C (2010) Alpha-synuclein nitration and autophagy response are induced in peripheral blood cells from patients with Parkinson disease. Neurosci Lett 477:6-10

Qin R, Li X, Li G, Tao L, Li Y, Sun J, Kang X, Chen J (2011) Protection by tetrahydroxystilbene glucoside against neurotoxicity induced by $\mathrm{MPP}+$ : the involvement of PI3K/Akt pathway activation. Toxicol Lett 202:1-7

Raza H, John A, Brown EM, Benedict S, Kambal A (2008) Alterations in mitochondrial respiratory functions, redox metabolism and apoptosis by oxidant 4-hydroxynonenal and antioxidants curcumin and melatonin in PC12 cells. Toxicol Appl Pharmacol 226:161-168

Reeve A, Simcox E, Turnbull D (2014) Ageing and Parkinson's disease: why is advancing age the biggest risk factor? Ageing Res Rev 14: $19-30$

Rodriguez-Blanco J, Martin V, Herrera F, García-Santos G, Antolín I, Rodriguez C (2008) Intracellular signaling pathways involved in post-mitotic dopaminergic $\mathrm{PC} 12$ cell death induced by 6 hydroxydopamine. J Neurochem 107:127-140

Rosso P, Fioramonti M, Fracassi A, Marangoni M, Taglietti V, Siteni S, Segatto M (2016) AMPK in the central nervous system: physiological roles and pathological implications. Res Rep Biol 7:1-13

Schulz J (2006) Anti-apoptotic gene therapy in Parkinson's disease. Parkinsonism\&nbsp;Relat Disord 70:467-476

Serviddio G, Davide Romano A, Cassano T, Bellanti F, Altomare E, Vendemiale G (2011) Principles and therapeutic relevance for targeting mitochondria in aging and neurodegenerative diseases. Curr Pharm Des 17:2036-2055

Strober W (1997) Trypan blue exclusion test of cell viability. Curr Protoc Immunol 21:a:3B. 1-a-3B3B. 2

Tamilselvam K, Braidy N, Manivasagam T, Essa MM, Prasad NR, Karthikeyan S, Thenmozhi AJ, Selvaraju S, Guillemin GJ (2013) Neuroprotective effects of hesperidin, a plant flavanone, on rotenone-induced oxidative stress and apoptosis in a cellular model for Parkinson's disease. Oxidative Med Cell Longev 2013:1-11

Tasaki Y, Omura T, Yamada T, Ohkubo T, Suno M, Iida S, Sakaguchi T, Asari M, Shimizu K, Matsubara K (2010) Meloxicam protects cell damage from 1-methyl-4-phenyl pyridinium toxicity via the phosphatidylinositol 3-kinase/Akt pathway in human dopaminergic neuroblastoma SH-SY5Y cells. Brain Res 1344:25-33 
Timmons S, Coakley MF, Moloney AM, O’Neill C (2009) Akt signal transduction dysfunction in Parkinson's disease. Neurosci Lett 467: 30-35

Venderova K, Park DS (2012) Programmed cell death in Parkinson's disease. Cold Spring Harb Perspect Med 2:a009365

Wang J, Whiteman MW, Lian H, Wang G, Singh A, Huang D, Denmark $\mathrm{T}$ (2009) A non-canonical MEK/ERK signaling pathway regulates autophagy via regulating Beclin 1. J Biol Chem 284:21412-21424

Wen Z, Zhang J, Tang P, Tu N, Wang K, Wu G (2018) Overexpression of miR-185 inhibits autophagy and apoptosis of dopaminergic neurons by regulating the AMPK/mTOR signaling pathway in Parkinson's disease. Mol Med Report 17:131-137

White E (2008) Autophagic cell death unraveled: pharmacological inhibition of apoptosis and autophagy enables necrosis. Autophagy 4: 399-401

Xilouri M, Stefanis L (2011) Autophagic pathways in Parkinson disease and related disorders. Expert Rev Mol Med 13:1-21

Xu Y, Liu C, Chen S, Ye Y, Guo M, Ren Q, Liu L, Zhang H, Xu C, Zhou Q (2014) Activation of AMPK and inactivation of Akt result in suppression of mTOR-mediated S6K1 and 4E-BP1 pathways leading to neuronal cell death in in vitro models of Parkinson's disease. Cell Signal 26:1680-1689

Yoo H, Ku S-K, Baek Y-D, Bae J-S (2014) Anti-inflammatory effects of rutin on HMGB1-induced inflammatory responses in vitro and in vivo. Inflamm Res 63:197-206
Yorimitsu T, Klionsky DJ (2005) Autophagy: molecular machinery for self-eating. Cell Death Differ 12:1542-1552

Zhang L, Dong Y, Xu X, Xu Z (2012) The role of autophagy in Parkinson's disease. Neural Regen Res 7:141

Zhang W, He H, Song H, Zhao J, Li T, Wu L, Zhang X, Chen J (2016) Neuroprotective effects of Salidroside in the MPTP mouse model of Parkinson's disease: involvement of the PI3K/Akt/GSK3 $\beta$ pathway. J Parkinsons Dis 2016:1-9

Zhao Q, Ye J, Wei N, Fong C, Dong X (2016) Protection against MPP+induced neurotoxicity in SH-SY5Y cells by tormentic acid via the activation of PI3-K/Akt/GSK3 $\beta$ pathway. Neurochem Int 97:117123

Zhao J, Geng L, Chen Y, Wu C (2020) SNHG1 promotes MPP+-induced cytotoxicity by regulating PTEN/AKT/mTOR signaling pathway in SH-SY5Y cells via sponging miR-153-3p. Biol Res 53:1-11

Zhu JH, Guo F, Shelburne J, Watkins S, Chu CT (2003) Localization of phosphorylated ERK/MAP kinases to mitochondria and autophagosomes in Lewy body diseases. Brain Pathol 13:473-481

Zhu J-h, Horbinski C, Guo F, Watkins S, Uchiyama Y, Chu CT (2007) Regulation of autophagy by extracellular signal-regulated protein kinases during 1-methyl-4-phenylpyridinium-induced cell death. Am J Pathol 170:75-86

Publisher's note Springer Nature remains neutral with regard to jurisdictional claims in published maps and institutional affiliations. 